\title{
Optimization of crystal violet adsorption on common lilac tree leaf powder as natural adsorbent material
}

\author{
Mosoarca G. ${ }^{1}$, Vancea C. ${ }^{1 *}$, Popa S. ${ }^{1 *}$ and Boran S. ${ }^{1}$ \\ Timisoara, Romania \\ Received: 07/09/2021, Accepted: 23/11/2021, Available online: 17/01/2022 \\ *to whom all correspondence should be addressed: e-mail: cosmin.vancea@upt.ro, simona.popa@upt.ro \\ https://doi.org/10.30955/gnj.003951
}

1Politehnica University Timisoara, Faculty of Industrial Chemistry and Environmental Engineering, Bd. V. Parvan No. 6, 300223,

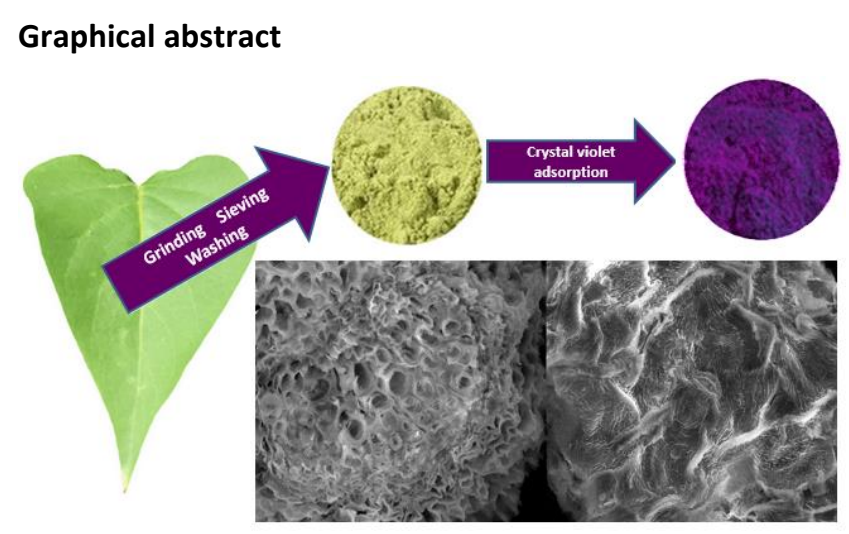

\section{ABSTRACT}

In this study the efficiency of crystal violet dye removal from aqueous solutions using lilac tree leaf powder as adsorbent material was tested. After adsorbent surface analysis by SEM and FTIR technics, the influence of six controllable factor on dye adsorption process was assesses using a L27 Taguchi experimental design. The optimum adsorption conditions and the controllable factors significance were established by evaluation of signal-to-noise ratio ( $\mathrm{S} / \mathrm{N})$. ANOVA analysis revealed the percentage contribution of each factor in crystal violet removal. Langmuir isotherm and pseudo-second order kinetic model characterized the process and the maximum adsorption capacity was higher than other similar adsorbents previously used in literature. The thermodynamic parameters reveal a favorable, spontaneous and endothermic adsorption based on physisorption mechanism.

Keywords: adsorption, crystal violet, isotherm, kinetic, Taguchi optimization, lilac tree leaf powder

\section{Introduction}

Dyes represent a wide range of chemicals that are widely used in various industries such as textiles, ceramics, food, cosmetics, pharmaceuticals, paper and printing (Aysu \& Kucuk, 2015; Fabryanty et al., 2017; Pang et al., 2019; Zamouche et al., 2020). Some dyes are not dangerous to humans and can be used in the food industry while others can severely affect the environment and human health.

Crystal violet dye is used to color textiles and paper and also in veterinary medicine as a biological stain and as an animal drug. It must be removed from wastewater because it is non-biodegradable, persists in the environment for longer time and can have toxic, mutagenic and carcinogenic effects (Aysu \& Kucuk, 2015; Chahinez et al., 2020; Chakraborty et al., 2011; Fabryanty et al., 2017; Zamouche et al., 2020; Franco et al., 2020; Shukat et al., 2017). Therefore, choosing an efficient and cheap treating method of these waters is essential to avoid pollution and protect the environment (Pang et al., 2020; Abbasi et al., 2020).

Several methods including coagulation-flocculation, catalytic reduction, photocatalytic degradation, microorganism degradation, membrane separation, membrane bioreactors, biological and electrochemical treatments have been used to removing dyes from aqueous solutions, but the relatively low efficiency of these methods, the need for special equipment and high energy consumption represent significant technical and economic disadvantages (Abbasi et al., 2020; Behboudi et al., 2021; Kosar Hashemi et al., 2021; Mosaviniya et al., 2019; Nouri et al., 2020; Tanzifi et al., 2020; Tanzifi et al., 2018a; Tanzifi et al., 2018b).

Adsorption is a successfully applied method for dyes removal from wastewater having many advantages: high efficiency, simplicity of operation, wide range of adsorbent material available and reduced costs (Chowdhury et al., 2013; Georgin et al., 2020; Rosly et al., 2021; Zehra et al., 2016). In recent years, the use of vegetable wastes (leaves, seeds, various peels and husk of fruit and agricultural products) as adsorbents material have become of particular interest, due to the fact that they are found in abundance, are ecological and have extremely low costs (Ali \& Muhammad, 2008; Bharathi \& Ramesh, 2012; Chakraborty et al., 2012; El-Sayed, 2011; Georgin et al., 2018; Ghazali, 2018; Jain \& Jayaram, 2010; Keereerak \& Chinpa, 2020; Kulkarni et al., 2017; Lim et al., 2015; Loulidi et al., 2020; Muhammad et al., 2019; Nieva 
et al., 2020; Pavan et al., 2014; Rammel et al., 2011; Saeed et al., 2010; Saha et al., 2012; Silveira et al., 2014; Smitha et al., 2012; Suyamboo \& Srikrishnaperumal, 2014; Wang et al., 2008).

Common lilac (Syringa vulgaris L.) is a large shrub or small tree, which grows up to a few meters tall, with a high ornamental value, much appreciated for the attractiveness of its wonderful and fragrant flowers. They can have shades ranging from pure white to purple intense. Originally from the Balkan Peninsula, it was naturalized, cultivated and used as an ornamental plant, in the temperate zone of Europe, Asia and North America. The bark, leaves, buds and flowers are used for phytotherapeutic purposes due to their antiinflammatory, antimicrobial and antihypertensive properties (Ba \& Kang, 2019; Jedrzejuk et al., 2016; Varga et al., 2019).

In this study the crystal violet dye was removed from the water by adsorption using as adsorbent material the common lilac leaf powder. One of the main objectives was to establish the optimum conditions of adsorption using the Taguchi method, following the influence of some controllable factors on the process efficiency and the signal/noise ratio $(\mathrm{S} / \mathrm{N})$. The contribution percentage of each parameter on dye removal process was determined by ANOVA analysis. Also, the accuracy of Taguchi model forecast was established. In addition, isotherms, kinetics and thermodynamics studies were conducted to evaluate the dye adsorption mechanism.

\section{Materials and methods}

In order to obtain the adsorbent material, mature leaves of common lilac tree were collected from Buzias resort, located in Timis County, Romania. The leaves powder obtaining process was described elsewhere (Mosoarca et al., 2020). The point of zero charge (PZC) for the adsorbent was 5.77 (Mosoarca et al., 2020). The characteristics of adsorbent material, before and after adsorption, were examined by SEM analysis (Quanta FEG 250 scanning electron microscope at $1600 x$ magnitude) and FTIR spectroscopy (Shimadzu Prestige-21 FTIR spectrophotometer).

The influence of various factors that influencing the adsorption process, on dye removal efficiency was studied, in batch system, according to the Taguchi approach (standard orthogonal array L27 as experimental design). These controllable factors and their levels are summarized in Table 1. The evaluation of the signal/noise ratio $(\mathrm{S} / \mathrm{N})$ was realized using the "larger is the better" option (Ghosh \& Mondal, 2019; Fernandez-Lopez, 2019; Santra, 2014; Zolgharnein \& Rastgordani, 2018). The percentage contribution of each factor to the dye removal efficiency was calculated with ANOVA analysis (Fernandez-Lopez, 2019; Rahmani et al., 2018; Zolgharnein \& Rastgordani, 2018). The mathematical operations were performed with the Minitab 19 Software.

All experiments were performed in the batch system, at a constant stirring intensity provided by a shaker. In order to obtain the best conditions for dye removal, the effect of changes of various parameters that may affect the adsorption process was examined. $\mathrm{NaOH}(0.1 \mathrm{~N})$ and $\mathrm{HCl}$ $(0.1 \mathrm{~N})$ solutions were used for $\mathrm{pH}$ adjustment. The dye concentration was determined with a UV-VIS spectrophotometer (Specord 200 PLUS) at $590 \mathrm{~nm}$. Three independent replicates were performed for each adsorption test.

Langmuir, Freundlich, Temkin, Sips and Redlich-Peterson isotherms non-linear equations (Dotto et al., 2017; Fabryanty et al., 2017; Filho et al., 2017; Lim et al., 2015; Piccin et al., 2017; Zaidi et al., 2018) and pseudo-first order and pseudo-second order kinetic models nonlinear equations (Dotto et al., 2017; Fabryanty et al., 2017; Filho et al., 2017; Lim et al., 2015; Piccin et al., 2017; Zaidi et al., 2018) were tested to analyze the adsorption equilibrium and kinetics. Also, the intraparticle kinetic model was analyzed and discussed (Abbasi et al., 2020; Suyamboo and Srikrishnaperumal, 2014). In order to have a better precision in the analysis of the results, besides the determination coefficient $\left(R^{2}\right)$, the error functions sum of square error (SSE), chi-square $\left(\chi^{2}\right)$ and average relative error (ARE) were also used (Piccin et al., 2017).

In order to characterize the process thermodynamically, the specific parameters (standard Gibbs free energy change, standard enthalpy change and standard entropy change) were computed at three temperatures (281, 294 and $308 \mathrm{~K}$ ) according with other previous studies (Ali et al., 2015; Fabryanty et al., 2017; Filho et al., 2017; Liu \& Xu, 2007; Liu \& Liu, 2008; Liu, 2009).

Table 1. Controllable factors and their levels

\begin{tabular}{cccc}
\hline Factor & Level 1 & Level 2 & Level 3 \\
\hline $\mathrm{pH}$ & 2 & 6 & 10 \\
\hline Time $(\mathrm{min})$ & 5 & 15 & 30 \\
\hline Adsorbent dose $\left(\mathrm{mg} \mathrm{L}^{-1}\right)$ & 0.5 & 1.5 & 2.5 \\
\hline $\begin{array}{c}\text { Initial dye concentration } \\
\left(\mathrm{mg} \mathrm{L}^{-1}\right)\end{array}$ & 50 & 150 & 250 \\
\hline Temperature $(\mathrm{K})^{-1}$ & 281 & 294 & 308 \\
\hline Ionic strength $\left(\mathrm{mol} \mathrm{L}^{-1}\right)$ & 0 & 0.1 & 0.2 \\
\hline
\end{tabular}

\section{Results and discussion}

\subsection{Adsorbent characterization}

The SEM image of the adsorbent material before adsorption (Figure 1a) shows an irregular surface with channels and many pores able to provide adsorption sites for dye molecules. After adsorption the SEM image is much different (Figure 1b), the surface has become smoother, and the pores are covered by dye molecules.

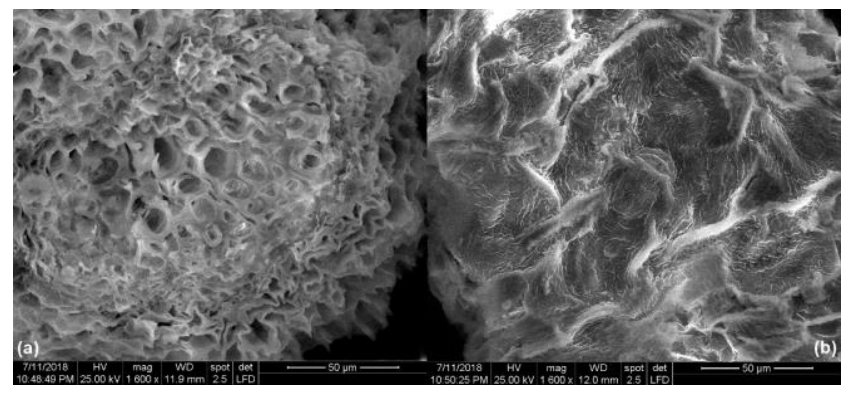

Figure 1. SEM image of adsorbent surface before (a) and after (b) crystal violet adsorption. 
Table 2. Experimental layout of $L 27$ orthogonal array and results obtained for removal efficiency and $S / \mathrm{N}$ ratios

\begin{tabular}{|c|c|c|c|c|c|c|c|}
\hline pH & Time (min) & $\begin{array}{l}\text { Adsorbent } \\
\text { dose }\left(\mathrm{g} \mathrm{L}^{-1}\right)\end{array}$ & $\begin{array}{c}\text { Initial dye } \\
\text { concentration }\left(\mathrm{mg} \mathrm{L}^{-1}\right) \\
\end{array}$ & Temperature (K) & $\begin{array}{c}\text { Ionic strength } \\
\left(\mathrm{mol} \mathrm{L}^{-1}\right)\end{array}$ & $\begin{array}{c}\text { Removal } \\
\text { efficiency (\%) }\end{array}$ & $\mathrm{S} / \mathrm{N}$ ratio \\
\hline 2 & 5 & 0.5 & 50 & 281 & 0 & 16.69 & 24.44 \\
\hline 2 & 5 & 0.5 & 50 & 294 & 0.1 & 14.73 & 23.36 \\
\hline 2 & 5 & 0.5 & 50 & 308 & 0.2 & 14.81 & 23.41 \\
\hline 2 & 15 & 1.5 & 150 & 281 & 0 & 26.27 & 28.38 \\
\hline 2 & 15 & 1.5 & 150 & 294 & 0.1 & 23.19 & 27.30 \\
\hline 2 & 15 & 1.5 & 150 & 308 & 0.2 & 23.85 & 27.54 \\
\hline 2 & 30 & 2.5 & 250 & 281 & 0 & 27.90 & 28.91 \\
\hline 2 & 30 & 2.5 & 250 & 294 & 0.1 & 24.62 & 27.82 \\
\hline 2 & 30 & 2.5 & 250 & 308 & 0.2 & 25.33 & 28.07 \\
\hline 6 & 5 & 1.5 & 250 & 281 & 0.1 & 49.30 & 33.85 \\
\hline 6 & 5 & 1.5 & 250 & 294 & 0.2 & 52.70 & 34.43 \\
\hline 6 & 5 & 1.5 & 250 & 308 & 0 & 69.02 & 36.77 \\
\hline 6 & 15 & 2.5 & 50 & 281 & 0.1 & 64.78 & 36.22 \\
\hline 6 & 15 & 2.5 & 50 & 294 & 0.2 & 69.24 & 36.80 \\
\hline 6 & 15 & 2.5 & 50 & 308 & 0 & 90.70 & 39.15 \\
\hline 6 & 30 & 0.5 & 150 & 281 & 0.1 & 44.05 & 32.87 \\
\hline 6 & 30 & 0.5 & 150 & 294 & 0.2 & 47.08 & 33.45 \\
\hline 6 & 30 & 0.5 & 150 & 308 & 0 & 61.67 & 35.80 \\
\hline 10 & 5 & 2.5 & 150 & 281 & 0.2 & 55.57 & 34.89 \\
\hline 10 & 5 & 2.5 & 150 & 294 & 0 & 75.63 & 37.57 \\
\hline 10 & 5 & 2.5 & 150 & 308 & 0.1 & 64.25 & 36.15 \\
\hline 10 & 15 & 0.5 & 250 & 281 & 0.2 & 40.41 & 32.12 \\
\hline 10 & 15 & 0.5 & 250 & 294 & 0 & 54.99 & 34.80 \\
\hline 10 & 15 & 0.5 & 250 & 308 & 0.1 & 46.72 & 33.39 \\
\hline 10 & 30 & 1.5 & 50 & 281 & 0.2 & 64.20 & 36.15 \\
\hline 10 & 30 & 1.5 & 50 & 294 & 0 & 87.37 & 38.82 \\
\hline 10 & 30 & 1.5 & 50 & 308 & 0.1 & 74.23 & 37.41 \\
\hline
\end{tabular}

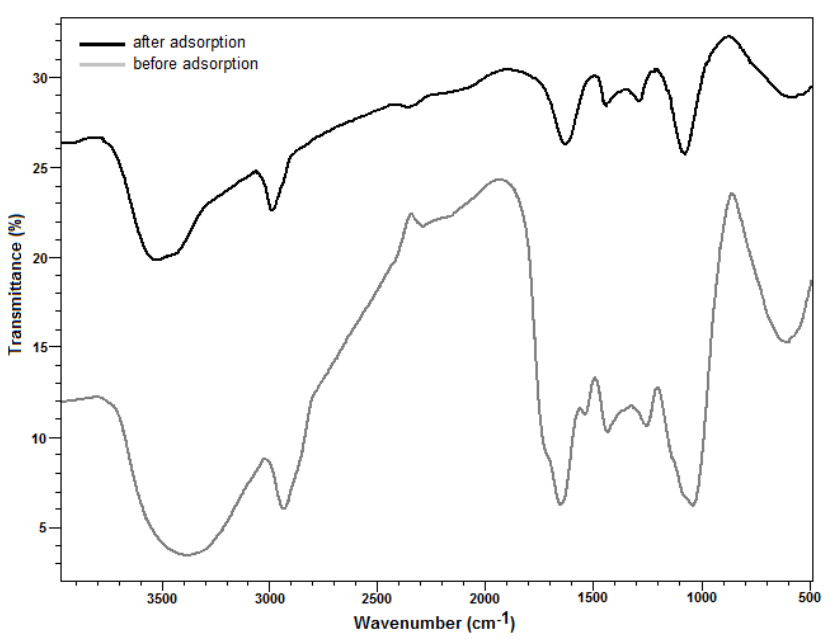

Figure 2. FTIR spectrum of common lilac tree leaves powder before and after crystal violet adsorption.

Following the FTIR analysis it was found that cellulose, hemicellulose and lignin are the main components of the adsorbent material (Mosoarca et al., 2020). The FTIR spectra of adsorbent before and after adsorption, shown in Figure 2, indicates specific peaks for main functional group existing in cellulose $\left(3382 \mathrm{~cm}^{-1}, 2933 \mathrm{~cm}^{-1}, 1026 \mathrm{~cm}^{-}\right.$ $1,609 \mathrm{~cm}^{-1}$ ) (Ali et al., 2015; Garg et al., 2007; Lupoi et al., 2015; Miraboutalebi et al., 2017; Moosavinejad et al., 2019), hemicellulose $\left(2933 \mathrm{~cm}^{-1}, 1647 \mathrm{~cm}^{-1}, 1255 \mathrm{~cm}^{-1}\right.$, $1026 \mathrm{~cm}^{-1}$ ) (Lupoi et al., 2015; Moosavinejad et al., 2019; Saravanakumar et al., 2014; Senthamaraikannan et al.,
2019; Shaharuddin et al., 2014; Weng et al., 2009) and lignin (3382 cm $, 2933 \mathrm{~cm}^{-1}, 1647 \mathrm{~cm}^{-1}, 1422 \mathrm{~cm}^{-1}$ ) (Miraboutalebi et al., 2017; Moosavinejad et al., 2019; Senthamaraikannan et al., 2019; Shaharuddin et al., 2014; Chang et al., 2015; Sahoo et al., 2011).

\subsection{Optimization parameters of adsorption process using Taguchi approach}

The optimum conditions for crystal violet removal from water were established using a L27 orthogonal array Taguchi design. The effect of 27 experiments, conducted according to the specified orthogonal array table, on the dye removal efficiency and the signal to noise $(\mathrm{S} / \mathrm{N})$ ratios is reveal in Table 2 .

Depending on the combination of the controllable factors the removal efficiency ranged from 14.73 to $90.70 \%$. The value of $\mathrm{S} / \mathrm{N}$ ratio increase with the increasing of $\mathrm{pH}$, time, adsorbent dose and temperature, while the increase of the initial dye concentration and ionic strength has a negative effect on this parameter (Figure 3 ). Also, Figure 3 reveals that the strongest variation in $\mathrm{S} / \mathrm{N}$ ratio occurred with $\mathrm{pH}$ followed by adsorbent dose, ionic strength, contact time, temperature and initial dye concentration. Therefore, the controllable factor with the greatest influence was the $\mathrm{pH}$ and the factor with the least influence was the initial dye concentration. The optimum conditions for dye removal, indicate by the maximum mean of S/N ratio were: $\mathrm{pH}=10$, contact time 30 minutes, 
adsorbent dose $2.5\left(\mathrm{~g} \mathrm{~L}^{-1}\right)$, initial dye concentration $50(\mathrm{mg}$ $\left.\mathrm{L}^{-1}\right)$, temperature $308 \mathrm{~K}$ and ionic strength $0.0\left(\mathrm{~mol} \mathrm{~L}^{-1}\right)$.

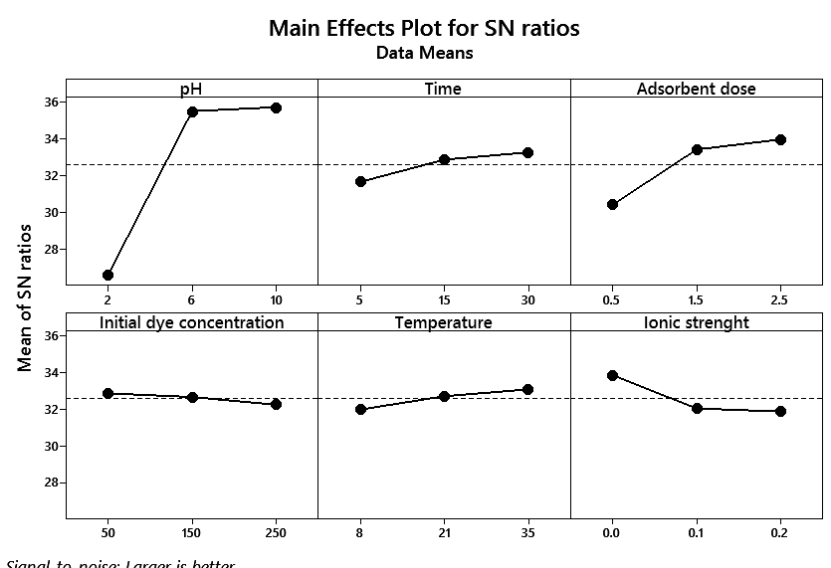

Figure 3. Signal-to-noise main effect plots for each controllable factors.

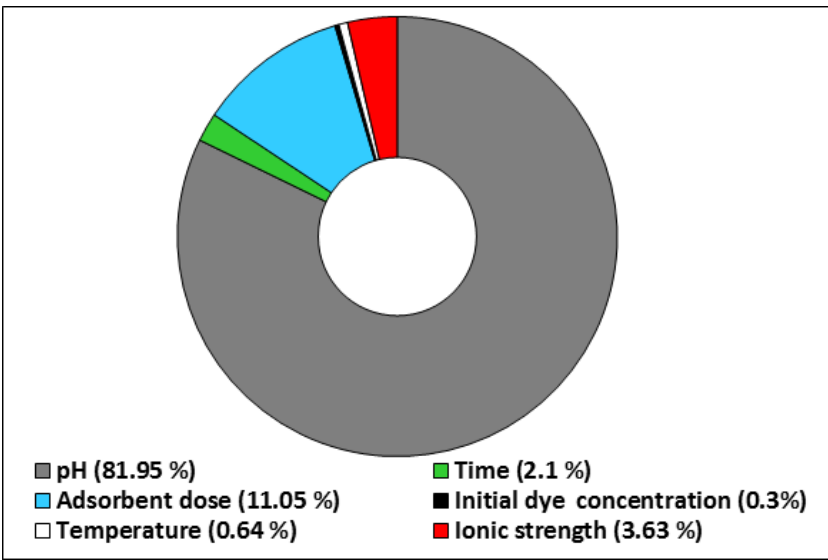

Figure 4. Contribution percentage of controllable factor influence on dye removal establish by ANOVA analysis.

The results of the analysis of variance (ANOVA), carried out to assess the contribution of each controllable factor to the process, are presented in Figure 4. They confirm the same order of influence for the controllable factors, the $\mathrm{pH}$ having the highest contribution percentage and the initial concentration the lowest percentage.

In order to establish the accuracy of Taguchi model forecast, the predicted values of dye removal efficiency were correlated with the experimental ones. Figure 5 indicate a very good correlation between the values and confirm the Taguchi method precision.

\subsection{Equilibrum and kinetic studies}

Langmuir, Freundlich, Temkin, Sips and Redlich-Peterson adsorption isotherms (Figure 6) were used to study the interactions between the dye and the adsorbent material as well as to obtain information about the adsorption mechanism (Alizadeh et al., 2017; Aysu \& Kucuk, 2015; Laskar \& Kumar, 2018; Lim et al., 2015; Mirza \& Ahmad, 2020; Zaidi et al., 2018).

The values for determination coefficient $\left(R^{2}\right)$, sum of square error (SSE), chi-square $\left(\chi^{2}\right)$ and average relative error (ARE) are summarized in Table 3 . The data suggest that the adsorption process is best described by the Langmuir isotherm. In addition, the value for the $R_{L}$ parameter (0.26) was calculated and this indicated that the adsorption is favorable.

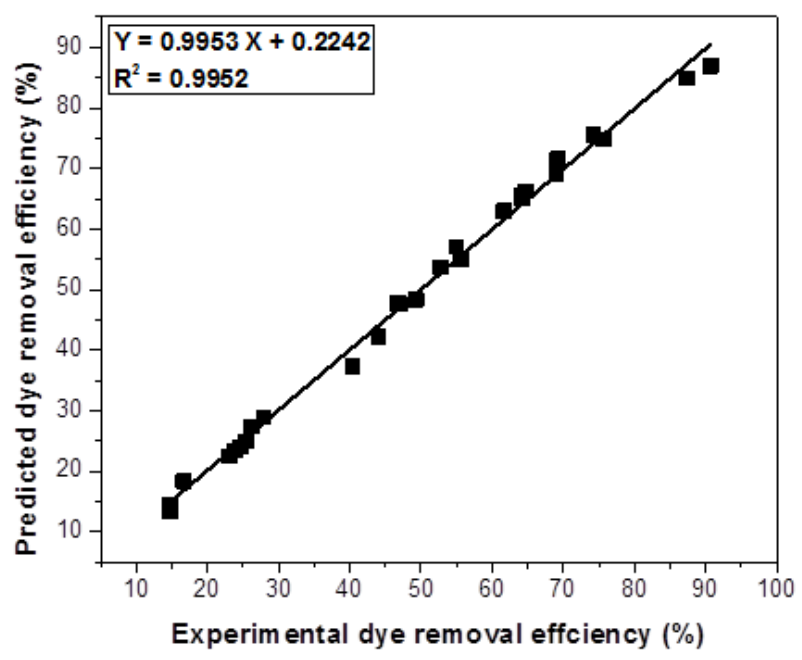

Figure 5. Comparison of experimental and predicted dye removal efficiency.

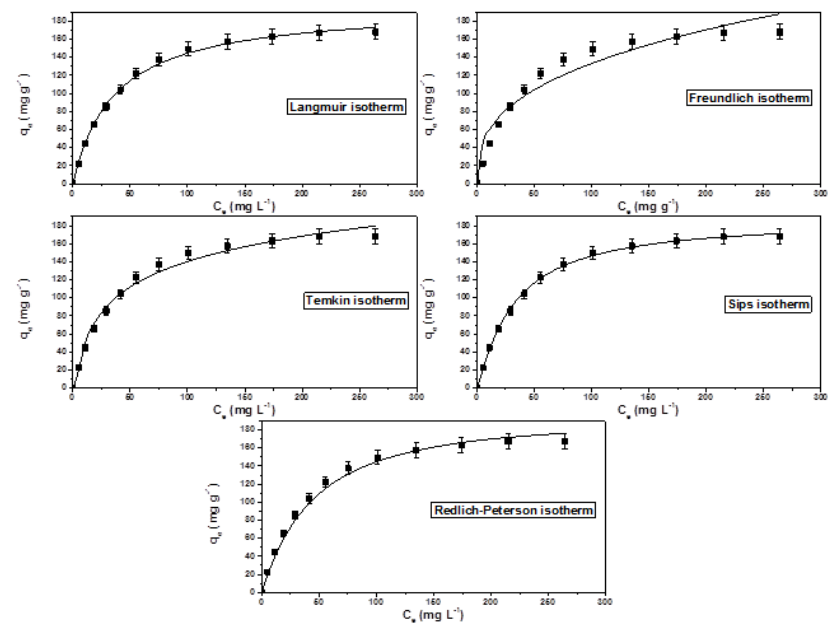

Figure 6. The tested adsorption isotherms (non-linear forms) for the crystal violet adsorption on common lilac tree leaves powder.

Table 4 compares the maximum adsorption capacities for different low-cost adsorbents used for crystal violet adsorption. The value of the maximum adsorption capacity obtained for common lilac tree leaves powder, $196.75\left(\mathrm{mg} \mathrm{g}^{-1}\right)$, is higher than other similar adsorbents previously reported in the literature.

The pseudo-first-order, pseudo-second-order and intraparticle diffusion models were used to study the adsorption kinetics (Figures 7 and 8). The kinetic parameters of these models can provide useful information needed to predict the adsorption rate and design the adsorption processes (Abbasi et al., 2020; Alizadeh et al., 2017; Laskar \& Kumar, 2018; Patil et al., 2020). Kinetic constants and the corresponding error functions presented in Table 5 indicate that the pseudosecond-order model best characterizes the process. The similar conclusion has been reported in other articles concerning the dyes adsorption on low-cost adsorbent materials (Chakraborty et al., 2012; Filho et al., 2017; Loulidi et al., 2020; Pavan et al., 2014; Smitha et al., 2012; Zamouche et al., 2020). 
The intra-particle kinetic model includes three steps. At the beginning of the process, the adsorption proceeds at high speed, the dye molecules immediately entering the large pores on the surface of the adsorbent. In step 2 the intra-particles diffusion proceeds with lower speed, the dye molecules entering the small pores of the adsorbent and then, in step 3 , the equilibrium is reached. The present finding indicate that intra-particle diffusion intervene in process but it is not the only one mechanism involved in adsorption (Abbasi et al., 2020; Suyamboo and Srikrishnaperumal, 2014).

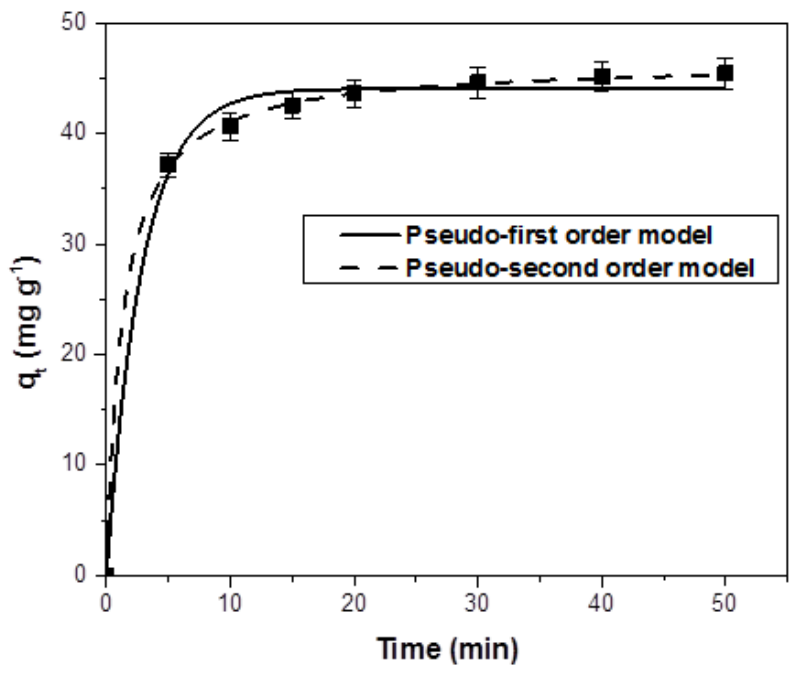

Figure 7. Pseudo-first-order and pseudo-second-order kinetic models (non-linear forms) for the crystal violet adsorption on common lilac tree leaves powder.

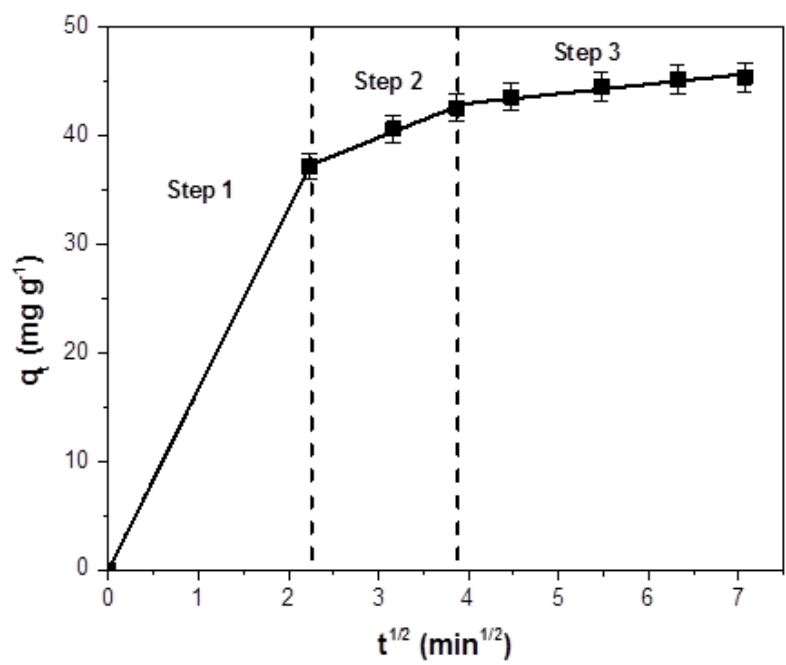

Figure 8. Fitted three-step intra-particle kinetic model for the crystal violet adsorption on common lilac tree leaves powder.

\subsection{Influence of initial solution $\mathrm{pH}$ on adsorption capacity}

The effect of initial $\mathrm{pH}$ of solution on the adsorption capacity is shown in Figure 9. The highest values of this parameter were obtained at $\mathrm{pH}>6$. Taking into account that pH pzc of adsorbent materials is 5.77 (Mosoarca et al., 2020), the better results can be explained by the fact that at higher $\mathrm{pH}$ values than $\mathrm{pH}$ PzC adsorbent surface is negative and binding of dye cations is favorable due to the electrostatic attractions (Fabryanty et al., 2017; Lim et al.,
2015; Rahmani et al., 2018; Zolgharnein and Rastgordani, 2018).

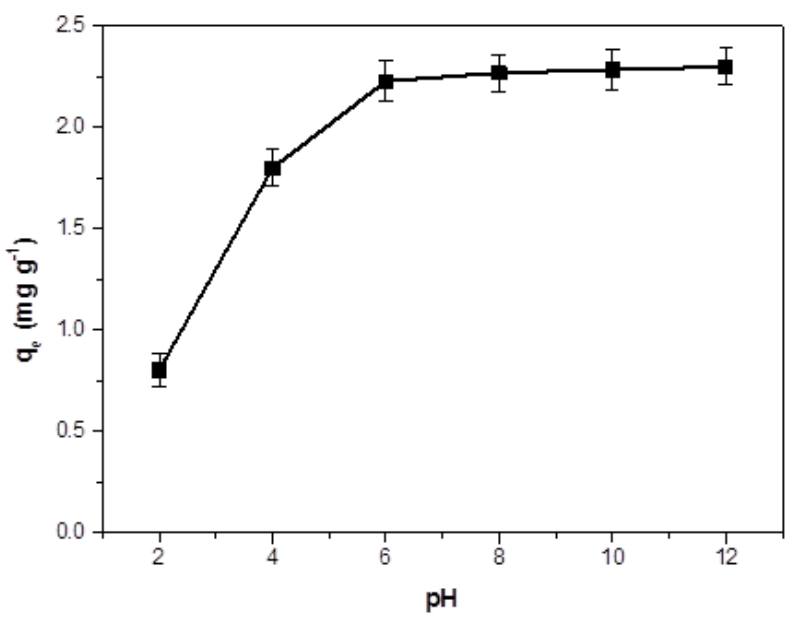

Figure 9. The effect of initial solution $\mathrm{pH}$ on adsorption capacity.

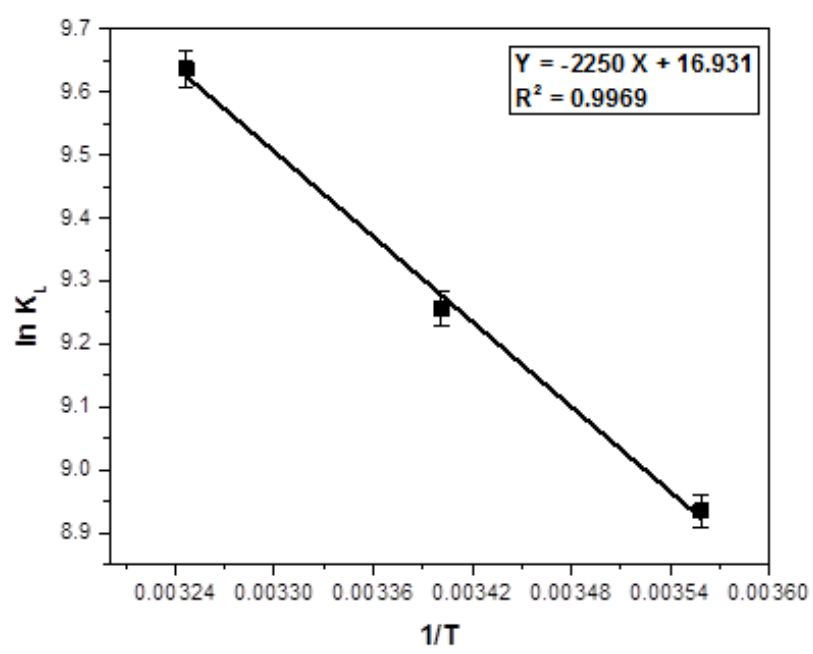

Figure 10. Plot of In $\mathrm{K}_{\mathrm{L}}$ Vs. $1 / \mathrm{T}$ for the crystal violet adsorption on common lilac tree leaves powder.

\subsection{Thermodynamic study}

Thermodynamic parameters were calculated from the slope and the intercept of In $\mathrm{K} L$ versus $1 / T$ plot (Figure 10), where: $\mathrm{K}_{\mathrm{L}}$ represents the Langmuir constant and $\mathrm{T}$ represents the absolute temperature (Ali et al., 2015; Fabryanty et al., 2017; Filho et al., 2017; Liu \& Xu, 2007; Liu \& Liu, 2008; Liu, 2009). The obtained values for these parameters are presented in Table 6 . The positive value of $\Delta \mathrm{H}^{0}$ and the negative value of $\Delta \mathrm{G}^{0}$ indicates that the dye adsorption on the adsorbent material is a favorable, spontaneous and endothermic process. In addition, the positive value of $\Delta S^{0}$ reveal the affinity of the adsorbent for the crystal violet dye (Aysu \& Kucuk, 2015; Fabryanty et al., 2017; Loulidi et al., 2020). The same observations have been reported in other studies in which similar adsorbents were used to remove crystal violet dye from water (Filho et al., 2017; Kulkarni et al., 2017; Loulidi et al., 2020; Zaidi et al., 2018). The value of $\Delta \mathrm{H}^{0}$ less than 20 ( $\mathrm{kJ} \mathrm{mol}{ }^{-1}$ ) shows that the dye removal mechanism is mainly physical adsorption and van der Waals interaction in involved in the physisorption (Jiang \& Hu, 2019; Loulidi et al., 2020; Zehra et al., 2016). 
Table 3. Adsorption isotherms models constants and the corresponding error functions

\begin{tabular}{|c|c|c|}
\hline Isotherm model & Parameters & Value \\
\hline \multirow{6}{*}{ Langmuir non-linear } & $\mathrm{K}_{\mathrm{L}}\left(\mathrm{L} \mathrm{mg}^{-1}\right)$ & $0.027 \pm 0.001$ \\
\hline & $q_{\max }\left(\mathrm{mg} \mathrm{g}^{-1}\right)$ & $196.7 \pm 4.21$ \\
\hline & $\mathrm{R}^{2}$ & 0.9984 \\
\hline & $\chi^{2}$ & 0.55 \\
\hline & SSE & 48.01 \\
\hline & ARE (\%) & 2.16 \\
\hline \multirow{6}{*}{ Freundlich non-linear } & $\mathrm{K}_{\mathrm{f}}\left(\mathrm{mg} \mathrm{g}^{-1}\right)\left(\mathrm{L}^{1 / \mathrm{n}} \mathrm{mg}^{-1 / \mathrm{n}}\right)$ & $9.07 \pm 1.29$ \\
\hline & $1 / \mathrm{n}$ & $0.66 \pm 0.03$ \\
\hline & $\mathrm{R}^{2}$ & 0.9256 \\
\hline & $\chi^{2}$ & 28.82 \\
\hline & SSE & 2215 \\
\hline & ARE (\%) & 13.02 \\
\hline \multirow{6}{*}{ Temkin non-linear } & $\mathrm{K}_{\mathrm{T}}\left(\mathrm{L} \mathrm{mg}^{-1}\right)$ & $0.313 \pm 0.001$ \\
\hline & $\mathrm{b}\left(\mathrm{kJ} \mathrm{g}^{-1}\right)$ & $60.06 \pm 2.14$ \\
\hline & $\mathrm{R}^{2}$ & 0.9838 \\
\hline & $\chi^{2}$ & 4.40 \\
\hline & SSE & 470 \\
\hline & ARE (\%) & 6.03 \\
\hline \multirow{7}{*}{ Sips non-linear } & $\mathrm{Q}_{\text {sat }}\left(\mathrm{mg} \mathrm{g}^{-1}\right)$ & $186.9 \pm 5.1$ \\
\hline & $\mathrm{K}_{\mathrm{S}}\left(\mathrm{L} \mathrm{mg}^{-1}\right)$ & $0.019 \pm 0.002$ \\
\hline & $\mathrm{n}$ & $1.13 \pm 0.03$ \\
\hline & $\mathrm{R}^{2}$ & 0.9981 \\
\hline & $\chi^{2}$ & 0.89 \\
\hline & SSE & 95.12 \\
\hline & ARE (\%) & 2.69 \\
\hline \multirow{7}{*}{ Redlich-Peterson non-linear } & $\mathrm{K}_{\mathrm{RP}}\left(\mathrm{L} \mathrm{g}^{-1}\right)$ & $4.12 \pm 0.03$ \\
\hline & $a_{R P}\left(L^{m} g^{-1}\right)$ & $0.014 \pm 0.001$ \\
\hline & $\beta_{\mathrm{RP}}$ & $1.06 \pm 0.02$ \\
\hline & $\mathrm{R}^{2}$ & 0.9947 \\
\hline & $\chi^{2}$ & 4.46 \\
\hline & SSE & 365 \\
\hline & ARE (\%) & 6.59 \\
\hline
\end{tabular}

Table 4. The maximum adsorption capacities for different low-cost adsorbents used for crystal violet adsorption

\begin{tabular}{|c|c|c|}
\hline Adsorbent material & Adsorption capacity $\left(\mathrm{mg} \mathrm{g}^{-1}\right)$ & Reference \\
\hline Calotropis procera leaf & 4.14 & (Ali \& Muhammad, 2008) \\
\hline Pineapple crown leaves & 6.49 & (Nieva et al., 2020) \\
\hline Corn stalk & 9.64 & (Muhammad et al., 2019) \\
\hline Almond shells & 12.20 & (Loulidi et al., 2020) \\
\hline Peel of Cucumis sativa fruit & 34.24 & (Smitha et al., 2012) \\
\hline Date palm leaves powder & 37.73 & (Ghazali et al., 2018) \\
\hline Rice bran & 41.68 & (Wang et al., 2008) \\
\hline Jackfruit leaf powder & 43.39 & (Saha et al., 2012) \\
\hline Punica granatum shell & 50.21 & (Silveira et al., 2014) \\
\hline Eragrostis plana nees & 60.10 & (Filho et al., 2017) \\
\hline Laminaria japonica & 66.64 & (Wang et al., 2008) \\
\hline Wheat bran & 69.15 & (Wang et al., 2008) \\
\hline Pineapple leaf powder & 78.22 & (Chakraborty et al., 2012) \\
\hline Palm kernel fiber & 78.90 & (El-Sayed, 2011) \\
\hline Pará chestnut husk & 83.60 & (Georgin et al., 2018) \\
\hline Papaya seeds & 85.99 & (Pavan et al., 2014) \\
\hline Wood apple shell & 129.87 & (Jain \& Jayaram, 2010) \\
\hline Breadfruit skin & 145.80 & (Lim et al., 2015) \\
\hline Moringa oleifera pod husk & 156.25 & (Keereerak \& Chinpa, 2020) \\
\hline Chaetophora elegans alga & 158.70 & (Rammel et al., 2011) \\
\hline Common lilac tree leaves powder & 196.75 & This study \\
\hline Grapefruit peel & 254.16 & (Saeed et al., 2010) \\
\hline Water hyacinth root powder & 322.58 & (Kulkarni et al., 2017) \\
\hline
\end{tabular}


Table 5. Kinetic models constants and the corresponding error functions

\begin{tabular}{|c|c|c|}
\hline Kinetic model & Parameters & Value \\
\hline \multirow{6}{*}{ Pseudo-first-order non-linear } & $\mathrm{k}_{1}\left(\min ^{-1}\right)$ & $0.39 \pm 0.03$ \\
\hline & $\mathrm{q}_{\mathrm{e}, \text { calc }}\left(\mathrm{mg} \mathrm{g}^{-1}\right)$ & $42.68 \pm 0.57$ \\
\hline & $R^{2}$ & 0.9925 \\
\hline & $\chi^{2}$ & 0.46 \\
\hline & SSE & 19.92 \\
\hline & ARE (\%) & 15.35 \\
\hline \multirow{6}{*}{ Pseudo-second-order non-linear } & $\mathrm{k}_{2}\left(\mathrm{~g} \mathrm{mg}^{-1} \mathrm{~min}^{-1}\right)$ & $0.017 \pm 0.007$ \\
\hline & $\mathrm{q}_{\mathrm{e}, \text { calc }}\left(\mathrm{mg} \mathrm{g}^{-1}\right)$ & $46.23 \pm 0.18$ \\
\hline & $\mathrm{R}^{2}$ & 0.9997 \\
\hline & $\chi^{2}$ & 0.01 \\
\hline & SSE & 0.53 \\
\hline & ARE (\%) & 13.00 \\
\hline
\end{tabular}

Table 6. Thermodynamic parameters for the crystal violet adsorption on common lilac tree leaves powder

\begin{tabular}{|c|c|c|c|c|}
\hline \multicolumn{3}{|c|}{$\Delta \mathrm{G}\left(\mathrm{kJ} \mathrm{mol}^{-1}\right)$} & \multirow[t]{2}{*}{$\Delta \mathrm{H}(\mathrm{kJ} \mathrm{mol}-1)$} & \multirow[t]{2}{*}{$\Delta \mathrm{S}\left(\mathrm{J} \mathrm{mol}^{-1}\right)$} \\
\hline $281 K$ & $294 \mathrm{~K}$ & $308 \mathrm{~K}$ & & \\
\hline-20.87 & -22.62 & -24.67 & 2.25 & 16.93 \\
\hline
\end{tabular}

\section{Conclusions}

The lilac tree leaf powder has a high efficiency on the crystal violet dye removal from aqueous solution. Using a Taguchi standard orthogonal array L27 as experimental design the optimum condition of adsorption were establish and it was concluded that the controllable factor with the greatest influence on the process was the $\mathrm{pH}$ and the factor with the least influence was the initial dye concentration. ANOVA analysis confirmed the results obtained by the Taguchi method. The correlation between the predicted values of dye removal efficiency and the experimental ones indicated a high accuracy of the Taguchi experimental design. The equilibrium and kinetics adsorption data can be best fitted by Langmuir isotherm and pseudo-second order kinetic model, respectively. The adsorbent material had a higher value of maximum adsorption capacity than other similar adsorbents used for crystal violet adsorption. The thermodynamic parameters indicate is a favorable, spontaneous and endothermic physisorption process.

\section{References}

Abbasi F., Tavakkoli Yaraki M., Farrokhnia A. and Bamdad M. (2020), Keratin nanoparticles obtained from human hair for removal of crystal violet from aqueous solution: Optimized by Taguchi method, International Journal of Biological Macromolecules, 143, 492-500.

Ali H. and Muhammad S.K. (2008), Biosorption of crystal violet from water on leaf biomass of Calotropis procera, Journal of Environmental Science and Technology, 1(3), 143-150.

Ali M.E., Yong C.K., Ching Y.C., Chuah C.H. and Liou N.S. (2015), Effect of single and double stage chemically treated kenaf fibers on mechanical properties of polyvinyl alcohol film, BioResources, 10(1), 822-838.

Alizadeh N., Shariati S. and Besharati N. (2017), Adsorption of crystal violet and methylene blue on Azolla and Fig leaves modified with magnetite iron oxide nanoparticles,
International Journal of Environmental Research, 11, 197206.

Aysu T. and Kucuk M.M. (2015), Removal of crystal violet and methylene blue from aqueous solutions by activated carbon prepared from Ferula orientalis, International Journal of Environmental Science and Technology, 12, 2273-2284.

Ba M. and Kang J. (2019), Effect of a fragrant tree on the perception of traffic noise, Building and Environment, 156, 147-155.

Behboudi G., Shayesteh K., Tavakkoli Yaraki M., Ali Ebrahimi H. and Moradi S. (2021), Optimized synthesis of lignin sulfonate nanoparticles by solvent shifting method and their application for adsorptive removal of dye pollutant, Chemosphere, 285, 131576.

Bharathi K.S. and Ramesh S.T. (2012), Biosorption of crystal violet from aqueous solution by Citrullus lanatus rind, Journal of Environmental Research and Development, 7(1A), 321-329.

Chahinez H.O., Abdelkader O., Leila Y. and Tran H.N. (2020), Onestage preparation of palm petiole-derived biochar: Characterization and application for adsorption of crystal violet dye in water, Environmental Technology \& Innovation, 19, 100872.

Chakraborty S., Chowdhury S. and Saha P.D. (2011), Adsorption of crystal violet from aqueous solution onto $\mathrm{NaOH}$-modified rice husk, Carbohydrate Polymers, 86(4), 1533-1541.

Chakraborty S., Chowdhury S. and Saha P.D. (2012), Insight into biosorption equilibrium, kinetics and thermo-dynamics of crystal violet onto Ananas comosus (pineapple) leaf powder, Applied Water Science, 2, 135-141.

Chang H.T., Yeh T.F., Hsu F.L., Kuo-Huang L.L., Lee C.M., Huang Y.S. and Chang S.T. (2015), Profiling the chemical composition and growth strain of giant bamboo (Dendrocalamus giganteus Munro), BioResources, 10(1), 1260-1270.

Chowdhury S., Chakraborty S. and Saha P.D. (2013), Removal of crystal violet from aqueous solution by adsorption onto Eggshells: equilibrium, kinetics, thermodynamics and artificial neural network modeling. Waste and Biomass Valorization, 4, 655-664.

Dotto G.L., Salau N.P.G., Piccin J.S., Cadaval T.R.S. and de Pinto L.A.A. (2017), Adsorption kinetics in liquid phase: Modeling for discontinuous and continuous systems, In: Adsorption Processes for Water Treatment and Purification, Bonilla- 
Petriciolet A., Mendoza-Castillo D. and Reynel-Avila H. (Eds.), Springer, Switzerland.

El-Sayed G.O. (2011), Removal of methylene blue and crystal violet from aqueous solutions by palm kernel fiber, Desalination, 272(1-3), 225-232.

Fabryanty R., Valencia C., Soetaredjo F.E., Putro J.N., Santoso S.P., Kurniawan A., Ju Y.H. and Ismadji S. (2017), Removal of crystal violet dye by adsorption using bentonite - alginate composite, Journal of Environmental Chemical Engineering, 5(6), 5677-5687.

Fernandez-Lopez J.A., Angosto J.M., Roca M.J. and Minarro M.D. (2019), Taguchi design-based enhancement of heavy metals bioremoval by agroindustrial waste biomass from artichoke, Science of The Total Environment, 653, 55-63.

Filho A.C.D., Mazzocato A.C., Dotto G.L., Thue P.S. and Pavan F.A. (2017), Eragrostis plana Nees as a novel eco-friendly adsorbent for removal of crystal violet from aqueous solutions, Environmental Science and Pollution Research, 24, 19909-19919.

Franco D.S.P., Fagundes J.L.S., Georgin J., Salaua N.P.G. and Dotto G.L. (2020), A mass transfer study considering intraparticle diffusion and axial dispersion for fixed-bed adsorption of crystal violet on pecan pericarp (Carya illinoensis), Chemical Engineering Journal, 397, 125423.

Garg U.K., Kaur M.P., Garg V.K. and Sud D. (2007), Removal of hexavalent chromium from aqueous solution by agricultural waste biomass, Journal of Hazardous Materials, 140(1-2), 60-68.

Ghazali A., Shirani M., Semnania A., Zare-Shahabadic V. and Nekoeiniad M. (2018), Optimization of crystal violet adsorption onto Date palm leaves as a potent biosorbent from aqueous solutions using response surface methodology and ant colony, Journal of Environmental Chemical Engineering, 6(4), 3942-3950.

Georgin J., Franco D.S.P., Netto M.S., Allasia D., Oliveira M.L.S. and Dotto G.L. (2020), Evaluation of Ocotea puberula bark powder (OPBP) as an effective adsorbent to uptake crystal violet from colored effluents: alternative kinetic approaches, Environmental Science and Pollution Research, 27, 2572725739.

Georgin J., Marques B.S., Peres E.C., Allasia D. and Dotto G.L. (2018), Biosorption of cationic dyes by pará chestnut husk (Bertholletia excelsa), Water Science \& Technology, 77(6), 1612-1621.

Ghosh S.B. and Mondal N.K. (2019), Application of Taguchi method for optimizing the process parameters for the removal of fluoride by Al-impregnated Eucalyptus bark ash, Environmental Nanotechnology, Monitoring \& Management, 11, 100206.

Jain S. and Jayaram R.V. (2010), Removal of basic dyes from aqueous solution by low-cost adsorbent: Wood apple shell (Feronia acidissima), Desalination, 250(3), 921-927.

Jedrzejuk A., Rabiza-Swider J., Skutnik E. and Lukaszewska A. (2016), Some factors affecting longevity of cut lilacs, Postharvest Biology and Technology, 111, 247-255.

Jiang Z. and Hu D. (2019), Molecular mechanism of anionic dyes adsorption on cationized rice husk cellulose from agricultural wastes, Journal of Molecular Liquids, 276, 105-114.

Keereerak A. and Chinpa W. (2020), A potential biosorbent from Moringa oleifera pod husk for crystal violet adsorption:
Kinetics, isotherms, thermodynamic and desorption studies, ScienceAsia, 46, 186-194.

Kosar Hashemi Y., Tavakkoli Yaraki M., Ghanbari S., Heidarpoor Saremi L. and Givianrad M.H. (2021), Photodegradation of organic water pollutants under visible light using anatase $\mathrm{F}$, $\mathrm{N}$ co-doped $\mathrm{TiO}_{2} / \mathrm{SiO}_{2}$ nanocomposite: Semi-pilot plant experiment and density functional theory calculations, Chemosphere, 275, 129903.

Kulkarni M.R., Revanth T., Anirudh A. and Bhat P. (2017), Removal of crystal violet dye from aqueous solution using water hyacinth: equilibrium, kinetics and thermodynamics study, Resource-Efficient Technologies, 3(1), 71-77.

Laskar N. and Kumar U. (2018), Adsorption of crystal violet from wastewater by modified Bambusa Tulda, KSCE Journal of Civil Engineering, 22, 2755-2763

Lim L.B.L., Priyantha N. and Mansor N.H.M. (2015), Artocarpus altilis (breadfruit) skin as a potential low-cost biosorbent for the removal of crystal violet dye: equilibrium, thermodynamics and kinetics studies, Environmental Earth Sciences, 73, 3239-3247.

Liu Y. and Xu H. (2007), Equilibrium, thermodynamics and mechanisms of $\mathrm{Ni}^{2+}$ biosorption by aerobic granules, Biochemical Engineering Journal, 35(2), 174-182.

Liu Y. and Liu Y.J. (2008), Biosorption isotherms, kinetics and thermodynamics, Separation and Purification Technology, 61(3), 229-242.

Liu Y. (2009), Is the Free Energy Change of Adsorption Correctly Calculated?, Journal of Chemical \& Engineering Data, 54(7), 1981-1985.

Loulidi I., Boukhlifi F., Ouchabi M., Amar A., Jabri M., Kali A., Chraibi S., Hadey C. and Aziz F. (2020), Adsorption of crystal violet onto an agricultural waste residue: kinetics, isotherm, thermodynamics and mechanism of adsorption, The Scientific World Journal, 2020, 5873521.

Lupoi J.S., Smith-Moritz A., Singh S., McQualter R., Scheller H.V., Simmons B.A. and Henry R.J. (2015), Localization of polyhydroxybutyrate in sugarcane using Fourier-transform infrared microspectroscopy and multivariate imaging, Biotechnology for Biofuels, 8, 98.

Miraboutalebi S.M., Nikouzad S.K., Peydayesh M., Allahgholi N., Vafajoo L. and McKay G. (2017), Methylene blue adsorption via maize silk powder: Kinetic, equilibrium, thermodynamic studies and residual error analysis, Process Safety and Environmental Protection, 106, 191-202.

Mirza A. and Ahmad R. (2020), An efficient sequestration of toxic crystal violet dye from aqueous solution by Alginate/Pectin nanocomposite: A novel and ecofriendly adsorbent, Groundwater for Sustainable Development, 11, 100373.

Moosavinejad S.M., Madhoushi M., Vakili M. and Rasouli D. (2019), Evaluation of degradation in chemical compounds of wood in historical buildings using FT-IR and FT-RA-MAN vibrational spectroscopy, Maderas. Ciencia y tecnologia, 21(3), 381-392.

Mosaviniya M., Kikhavani T., Tanzifi M., Tavakkoli Yaraki M., Tajbakhsh P. and Lajevardi A. (2019), Facile green synthesis of silver nanoparticles using Crocus Haussknechtii Bois bulb extract: Catalytic activity and antibacterial properties, Colloid and Interface Science Communications, 33, 100211.

Mosoarca G., Vancea C., Popa S., Gheju M. and Boran S. (2020), Syringa vulgaris leaves powder a novel low-cost adsorbent for methylene blue removal: isotherms, kinetics, 
thermodynamic and optimization by Taguchi method, Scientific Reports, 10, 17676.

Muhammad U.L., Zango Z.U., Kadir H.A. and Usman A. (2019), Crystal violet removal from aqueous solution using corn stalk biosorbent, Science World Journal, 14(1), 133-138.

Nieva A.D., Avena L.G.S., Pascual M.A.M. and Pamintuan K.R.S. (2020), Characterization of Powdered Pineapple (Ananas comosus) Crown Leaves as Adsorbent for Crystal Violet in Aqueous Solutions, IOP Conf. Series: Earth and Environmental Science, 563, 012010.

Nouri A., Tavakkoli Yaraki M., Lajevardi A., Rezaei Z., Ghorbanpour M. and Tanzifi M. (2020), Ultrasonic-assisted green synthesis of silver nanoparticles using Mentha aquatica leaf extract for enhanced antibacterial properties and catalytic activity, Colloid and Interface Science Communications, 35, 100252.

Pang X., Sellaoui L., Franco D., Dotto G.L., Georgin J., Bajahzar A., Belmabrouk H., Ben Lamine A., Bonilla-Petriciolet A. and Lia Z. (2019), Adsorption of crystal violet on biomasses from pecan nutshell, para chestnut husk, araucaria bark and palm cactus: Experimental study and theoretical modeling via monolayer and double layer statistical physics models, Chemical Engineering Journal, 378, 122101.

Pang X., Sellaoui L., Franco D., Netto M.S., Georgin J., Dotto G.L., Abu Shayeb M.K., Belmabrouk H., Bonilla-Petriciolet A. and Li Z. (2020), Preparation and characterization of a novel mountain soursop seeds powder adsorbent and its application for the removal of crystal violet and methylene blue from aqueous solutions, Chemical Engineering Journal, 391, 123617.

Pavan F.A., Camacho E.S., Lima E.C., Dotto G.L., Branco V.T.A. and Dias S.L.P. (2014), Formosa papaya seed powder (FPSP): preparation, characterization and application as an alternative adsorbent for the removal of crystal violet from aqueous phase, Journal of Environmental Chemical Engineering, 2(1), 230-238.

Patil S.R., Sutar S.S. and Jadhav J.P. (2020), Sorption of crystal violet from aqueous solution using live roots of Eichhornia crassipes: Kinetic, isotherm, phyto and cyto-genotoxicity studies, Environmental Technology \& Innovation, 18, 100648.

Piccin J.S., Cadaval T.R.S., de Pinto L.A.A. and Dotto G.L. (2017), Adsorption isotherms in liquid phase: Experimental, modeling and interpretations, In: Adsorption Processes for Water Treatment and Purification, Bonilla-Petriciolet A., Mendoza-Castillo D. and Reynel-Avila H. (Eds.), Springer, Switzerland.

Rahmani M., Kaykhaii M. and Sasani M. (2018), Application of Taguchi L16 design method for comparative study of ability of $3 \mathrm{~A}$ zeolite in removal of Rhodamine $B$ and Malachite green from environmental water samples, Spectrochimica Acta Part A: Molecular and Biomolecular Spectroscopy, 188, 164-169.

Rammel R.S., Zatiti S.A. and El-Jamal M.M. (2011), Biosorption of crystal violet by Chaetophora elegans alga, Journal of the University of Chemical Technology and Metallurgy, 46(3), 283-292.

Rosly N.Z., Abdullah A.H., Kamarudin M.A., Ashari S.E. and Ahmad S.A.A. (2021), Adsorption of methylene blue dye by calix[6]arene-modified lead sulphide (Pbs): optimisation using response surface methodology, International Journal of Environmental Research and Public Health, 18(2), 397.
Saeed A., Sharif M. and Iqbal M. (2010), Application potential of grapefruit peel as dye sorbent: kinetics, equilibrium and mechanism of crystal violet adsorption, Journal of Hazardous Materials, 179(1-3), 564-572.

Saha P.D., Chakraborty S. and Chowdhury S. (2012), Batch and continuous (fixed-bed column) bisorption of crystal violet by Artocarpus heterophyllus (jackfruit) leaf powder, Colloids and Surfaces B: Biointerfaces, 92, 262-270.

Sahoo S., Seydibeyoglu M.O., Mohanty A.K. and Misra M. (2011), Characterization of industrial lignins for their utilization in future value added applications, Biomass and Bioenergy, 35(10), 4230-4237.

Santra D., Joarder R. and Sarkar M. (2014), Taguchi design and equilibrium modeling for fluoride adsorption on cerium loaded cellulose nanocomposite bead, Carbohydrate Polymers, 111, 813-821.

Saravanakumar S.S., Kumaravel A., Nagarajan T. and Moorthy I.G. (2014), Effect of chemical treatments on physicochemical properties of Prosopis juliflora fibers, International Journal of Polymer Analysis and Characterization, 19, 383-390.

Senthamaraikannan P., Sanjay M.R., Bhat K.S., Padmaraj N.H. and Jawaid M. (2019), Characterization of natural cellulosic fiber from bark of Albizia amara, Journal of Natural Fibers, 16(8), 1124-1131.

Shaharuddin S., Razak S.I.A. and Muhamad I.I. (2014), Sugarcane bagasse as the potential agro-waste resource for the immobilization of Lactobacillus rhamnosus NRRL 442, Advanced Materials Research, 1043, 214-218.

Shukat S., Bhatti H.N., Iqbal M. and Noreen S. (2017), Mango stone biocomposite preparation and application for crystal violet adsorption: a mechanistic study, Microporous and Mesoporous Materials, 239, 180-189.

Silveira M.B., Pavan F.A., Gelos N.F., Lima E.C. and Dias S.L. (2014), Punica granatum shell preparation, characterization, and use for crystal violet removal from aqueous solution, Clean-Soil Air Water, 42(7), 939-946.

Smitha T., Thirumalisamy S. and Manonmani S. (2012), Equilibrium and kinetics study of adsorption of crystal violet onto the peel of Cucumis sativa fruit from aqueous solution, Journal of Chemistry, 9, 457632.

Suyamboo B.K. and Srikrishnaperumal R. (2014), Biosorption of crystal violet onto cyperus rotundus in batch system: kinetic and equilibrium modeling, Desalination and Water Treatment, 52(19-21), 3535-3546.

Tanzifi M., Tavakkoli Yaraki M., Beiramzadeh Z., Heidarpoor Saremi L., Najafifard M., Moradi H., Mansouri M., Karami M. and Bazgir H. (2020), Carboxymethyl cellulose improved adsorption capacity of polypyrrole/CMC composite nanoparticles for removal of reactive dyes: Experimental optimization and DFT calculation, Chemosphere, 255, 127052.

Tanzifi M., Tavakkoli Yaraki M., Karami M., Karimi S., Dehghani Kiadehi A., Karimipour K. and Wang S. (2018a), Modelling of dye adsorption from aqueous solution on polyaniline/carboxymethyl cellulose/ $\mathrm{TiO}_{2}$ nanocomposites, Journal of Colloid and Interface Science, 519, 154-173.

Tanzifi M., Tavakkoli Yaraki M., Kiadehi A.D., Hosseini S.H., Olazar M., Bhati A.K., Agarwal S., Gupta V.K. and Kazemi A. (2018b), Adsorption of Amido Black 10B from aqueous solution using polyaniline $/ \mathrm{SiO}_{2}$ nanocomposite: Experimental 
investigation and artificial neural network modeling, Journal of Colloid and Interface Science, 510, 246-261.

Varga E., Barabas C., Toth A., Boldizsar I., Noszal B. and Toth G. (2019), Phenolic composition, antioxidant and antinociceptiveactivities of Syringa vulgaris L. bark and leaf extracts, Natural Product Research, 33(11), 1664-1669.

Wang X.S., Liu X., Wen L., Zhou Y., Jiang Y. and Li Z. (2008), Comparison of basic dye crystal violet removal from aqueous solution by low-cost biosorbents, Separation Science and Technology, 43(14), 3712-3731.

Weng C.H., Lin Y.T. and Tzeng T.W. (2009), Removal of methylene blue from aqueous solution by adsorption onto pineapple leaf powder, Journal of Hazardous Materials, 170(1), 417-424.

Zaidi N.A.H.M., Lim L.B.L. and Usman A. (2018), Artocarpus odoratissimus leaf-based cellulose as adsorbent for removal of methyl violet and crystal violet dyes from aqueous solution, Cellulose, 25, 3037-3049.

Zamouche M., Habib A., Saaidia K. and Lehocine M.B. (2020), Batch mode for adsorption of crystal violet by cedar cone forest waste, SN Applied Sciences, 2, 198.

Zehra T., Priyantha N. and Lim L.B.L. (2016), Removal of crystal violet dye from aqueous solution using yeast-treated peat as adsorbent: thermodynamics, kinetics, and equilibrium studies. Environmental Earth Sciences, 75, 357.

Zolgharnein J. and Rastgordani M. (2018), Optimization of simultaneous removal of binary mixture of indigo carmine and methyl orange dyes by cobalt hydroxide nano-particles through Taguchi method, Journal of Molecular Liquids, 262, 405-414. 